\title{
A New Type of Aerostatic Thrust Bearing Controlled by High-speed Pneumatic Valve and a Novel Pressure Transducer
}

\author{
W. U. Rehman ${ }^{1}$, G. Jiang, ${ }^{1, *}$, Y. Wang ${ }^{1}$, N. Iqbal ${ }^{1}$, S. U. Rehman ${ }^{2}$, S. Bibi ${ }^{2}$ \\ and H. Elahi ${ }^{3}$ \\ ${ }^{1}$ School of Mechanical Engineering, Chongqing University, Chongqing China \\ ${ }^{2}$ Chemistry Department Agriculture University Faisalabad, Pakistan \\ ${ }^{3}$ Sapienza University of Rome, Rome, Italy \\ *Email: Gyjiang_1@163.com
}

\begin{abstract}
The current research work presents a low cost, efficient and innovative active aerostatic thrust bearing which is controlled through a combination of the Arduino board, feedback transducers and high-speed valves. The purpose is to make low cost, compact active aerostatic thrust bearing with overall small dimensions and compact size. A prototype design is done in solid works with small dimensions and components are produced with the help of the high precision machining process. There are two high-speed electropneumatic valves which are controlled through pulse width modulation techniques. These high-speed electro-pneumatic valves modify the supply pressure of aerostatic bearing to achieve desired air height gap. There are two novel pressure sensors which provide a feedback signal for control. The test bench to perform experiments has been explained. The performance of the proposed aerostatic bearing is checked both in open loop and closed loop configuration with respect to static and dynamic conditions.
\end{abstract}

Keywords: Aerostatic bearings; active control; load-carrying ability; aerostatic lubrication; Arduino; solenoid valves.

\section{INTRODUCTION}

Whenever there is a requirement of high accuracy, then the aerostatic bearing is thought to be the first option. The aerostatic bearings are used in a lot of precise measuring or positioning systems due to their property of low friction. It is used in high precision guideways and machines where coordinates are measured. However, aerostatic bearing presents low stiffness as compared to the hydrostatic bearing. Here, the literature presents some methods to improve the stiffness of traditional aerostatic bearing by using active or passive compensation.

In passive compensation methods, infinite stiffness is achieved with the help of a passive device. In the most recent stage in the development of aerostatic bearing, the passive compensated aerostatic bearing provides low bandwidth and gets infinite stiffness about $20 \%$ of load range [1]. Infinite stiffness in an aerostatic bearing is achieved by using deformation in a membrane which changes the air gap according to it [2]. Similarly, infinite stiffness in circular thrust bearing has been achieved through a combination of a spring plate, movable bush and two restrictors [3, 4]. A combination of disk and spring is used as a compensation device [5]. The static and dynamic characteristics of the aerostatic bearing are tried to improve by proposing a lumped parameter model. This model has the 
objective of the rapid design and sensitivity analysis for aerostatic bearings. The lumped parameter model has advantages over the distributed parameter model in term of accuracy and faster response [6]. Similar research has been carried out in [7] where static and dynamic characteristics are studied numerically and experimentally on the base of a dynamic model.

However, there are some problems with passive compensation, such as; it works under some specific conditions and operating points. Whenever the operating point changes, then system efficiency decreases. In other words, one can say that passive compensation has low bandwidth. In order to increase bandwidth active compensation is used. Active compensation has higher efficiency in term of operating under different points.

There are a lot of approaches in the literature which have been proposed for active compensation. Some of them use servo valve as the active device for active compensation to improve stiffness [8-10]. It is proved that stability of infinite stiffness aerostatic bearing can be increased by controlling the restrictor area with appropriate phase lag to change air gap [11]. Two kinds of restrictor using PZT are much more famous such as; active inherent restrictor and exhausted controlled restrictor. When we integrate active inherent restrictor to air bearing then they perform the job of movable nozzles and helps to attain pressure variation without changing supply pressure. The second restrictor is exhaust controlled restrictor [11] The exhaust control restrictor consists of a piezoelectric actuator, amplifier and preload screw. It controls the air gap by changing the coefficient of the exhaust channel [12]. It is also tried to control air bearing with exhausted controlled restrictor with help of displacement feedback, and aero-statically controlled restrictor which has pressure feedback $[13,14]$. Some prototypes were developed which use supply pressure, conicity and hybrid compensation as an advantage for active compensation. These prototypes have a central hole for air supply, a thin plate and cylindrical column for clamping purpose. Three piezoelectric actuators are used to control deflection in plates. The surface of active aerostatic bearing deforms into concave shape when the actuator extends. The deflection produces a change in air gap pressure, as a result, a change in bearing force [13, 15-17]. Active control for aerostatic journal bearing is proposed where compensation is achieved through sensor mounted on the sleeve of bearing [18]. Some authors also presented a compensation method called support method where piezo electric actuators are embedded into conventional aerostatic pad to obtain accurate and precise control for positions purpose [19, 20]. Similar efforts were made in [21] where piezoelectric actuators were used to control shaft radial stiffness. Unlike the previously mentioned method called support compensation method, this method obtained the control of the position of bearing with the help of the shape of air gap. Approaches to design conventional bearing use static characteristics while to achieve high-efficiency dynamic load variation must be considered as bearing faces dynamics load variation during operations [22-24]. So that is why numerical and analytical methods are used to guess the dynamic behaviour of the aerostatic bearing. At this step, the identification of coefficients for the aerostatic bearing is difficult [13]. A critical review has been presented for aerostatic bearing for active compensation [25].

The different researchers use different types of actuating devices or restrictors for active control or active compensation of aerostatic bearing. However, some of the good types of active devices are such as; PZT actuators, pneumatic valves, magnetic preloaded actuators and magneto restrictive elements [13, 26-28]. These papers present different types of approaches for active compensation using experimental or theoretical procedure. Although a lot of efforts have been made in this field of research no one can propose 
commercial solutions to achieve low cost active aerostatic bearing. Still, a lot of researchers are trying to find the solution to integrate active devices with aerostatic bearing and making it a low cost.

Automatic control systems (Mechatronics systems) are getting popularity over decades [27-30]. The current research shows a mechatronics prototype. This prototype is developed for active aerostatic thrust bearing and challenge is to prove the feasibility of proposed active aerostatic thrust bearing with low cost as well as having embedded features. A rectangular pad has embedded digital valves (actuators) and sensors and an Arduino board which is used as a controller. High-speed mini solenoid valves due to their best fast dynamic characteristics are employed with pulse width modulation technique (PWM) for controlling bearing supply pressure. In order to achieve high sensitivity, an embedded back-pressure sensor is designed which measures the air gap in the form of the feedback signal. In order to reduce the cost, a small, low cost and compact system is designed in solid works with some commercial components. Experiments have been performed on the assembled system, both in open-loop and closed-loop configuration, under dynamic and static condition.

\section{PROTOTYPE FOR AEROSTATIC ACTIVE THRUST BEARING}

The active aerostatic bearing presented in this article consists of two main components such as; embedded pressure sensor and aerostatic thrust pad. The aerostatic pad is rectangular with dimensions $75 \times 50 \times 15$. It is designed in solid work and manufactured with a high precision machining process. Cross-section view of the aerostatic pad is shown in Figure 1.

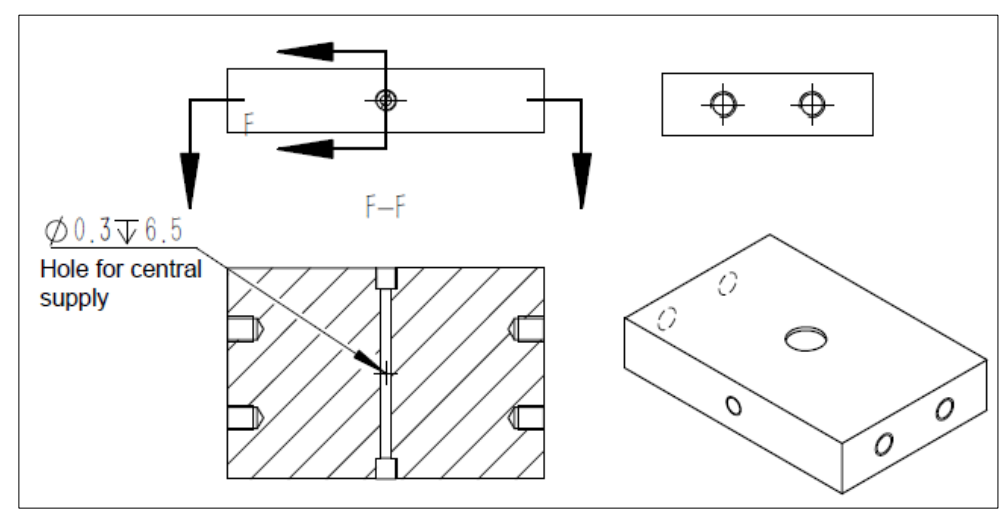

Figure 1. Aerostatic pad and its cross-sectional view in solid works.

The lower surface of bearing has a single hole of diameter $0.3 \mathrm{~mm}$ which acts as recess or capillary restrictor, serve to maintain certain height or air gap under bearing lower surface. The active aerostatic thrust bearing is made of aluminium alloy, due to property of lightweight and good structural stiffness. Some important components of the active aerostatic thrust bearing are (1) aerostatic pad (2) electro-pneumatic valve (3) electro-pneumatic valve (4) Arduino board (5) pressure sensor, as shown in Figure 2. An active aerostatic thrust bearing is attached with two electro-pneumatic high-speed digital valves. Both electro-pneumatic valves are initially closed configuration. An Arduino board is used to control the opening and closing of valves by using PWM techniques which in fact changes duty cycles to adjust flow through the valves. 


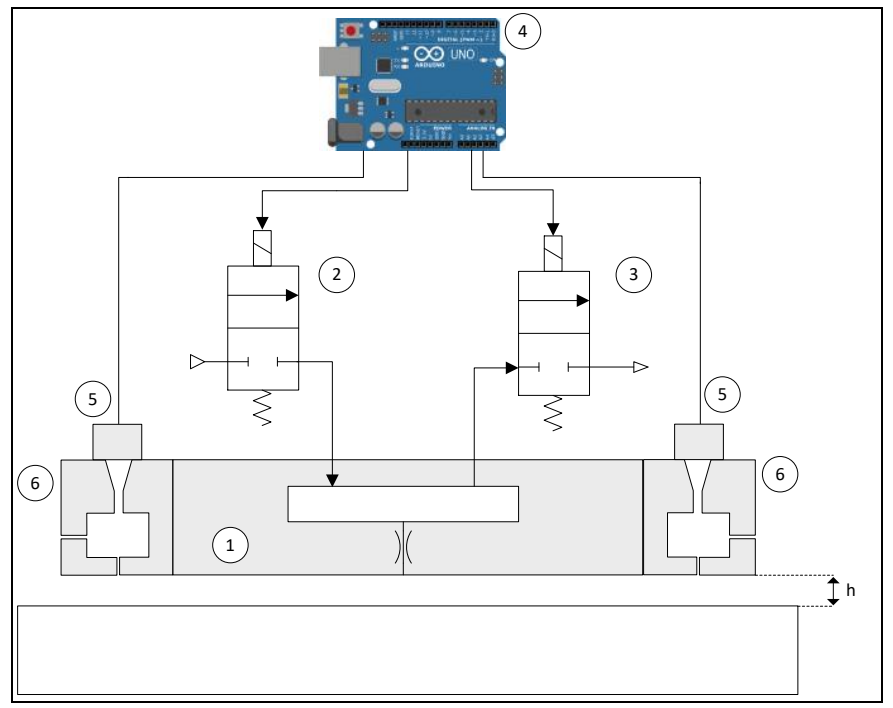

Figure 2. Schematic of active aerostatic thrust bearing (1) with inlet valve (2) and outlet valve (3), Arduino board (4), pressure transducer (5) and pressure sensor (6)

There are two types of compensation, passive compensation and active compensation. In passive compensation, valve (2) is kept completely open and valve (3) is kept completely closed. While in active compensation, duty cycles of both valves are controlled by PWM techniques, so that the desired air gap can be achieved by adjusting duty cycles using PWM techniques. The pressure sensor is used to measure height $h$ of air gap which is formed under the aerostatic pad. The pressure sensor measures the air gap with the help of pressure transducer which takes feedback and gives it to the Arduino board. The digital high-speed electro-pneumatic valves and their cross-section are shown in Figure 3(a)

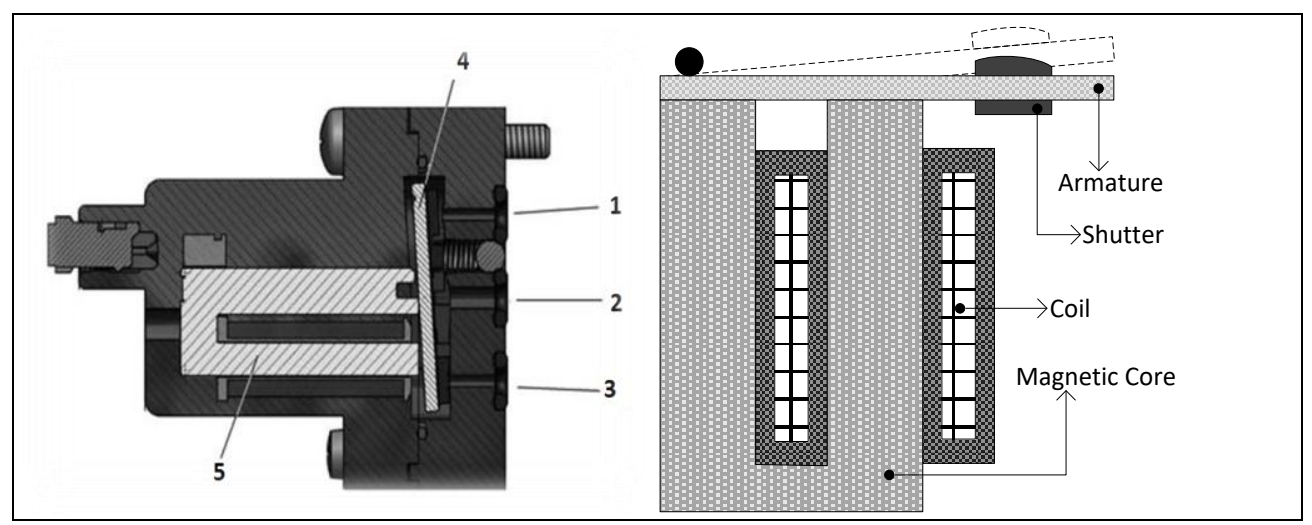

(a) schematic

(b) cross-sectional

Figure 3. Electro-pneumatic valve.

Both valves are a three-port, two-way valve. The electro-pneumatic valve consists of internal anchor (4) which is controlled by electromagnetic (5) and it is pivoted to the output port (2), supply port (3) and exhaust port (1). A plug is used to block the exhaust port so that electro-pneumatic valve can be used as two-port and two way normally closed valve. A pneumatic solenoid valve is an electromechanically controlled valve. It has the feature of the solenoid which is an electrical coil accompanied by a magnetic core in its 
centre. When an electric current is given to coil then it creates a magnetic field through the help of magnetic core in its centre, as a result, it produces motion of shutter which close or open the valve as shown in Figure 3(b). In the active configuration for the aerostatic thrust bearing, an Arduino board takes the average value of the signals which is given by pressure transducers, mounted on the pressure sensor. This signal is used to measure the height of the air gap formed under the aerostatic pad. The average value of the signal is compared with the reference signal, it generates an error after comparison is processed by the Arduino controller to produce control logics. There is also the possibility to control the two valves separately by using the feedback signal generated by their respective pressure transducer. Each signal is used by their corresponding proportional controller.

The pressure sensor is a self-designed sensor in solid work and manufactured with high precision machining operations. Schematic diagram of the pressure sensor is shown in Figure 4. The pressure sensor is made of aluminum alloy due to good stiffness/weight ratio. Pressure sensor has an internal space or chamber. This chamber is connected to pressure transducer, incoming supply and an outlet. The outlet is a hole of diameter of $400 \mu \mathrm{m}$. This hole opens from the lower surface side so that it can measure the air gap formed active aerostatic thrust pad. The internal cylindrical surface is a chamber of diameter $3 \mathrm{~mm}$. This chamber creates a pressure called $P_{c}$ where subscript c denotes chamber. Pressure $P_{c}$ depends upon external supply pressure $P_{S}$ and height under aerostatic thrust bearing $h$. 3D and cross-sectional view of the pressure sensor is shown in Figure 5 where (a) shows a top view of pressure sensor, (b) shows 3D view of pressure sensor, (c) shows cross-sectional view of the presser sensor while (d) shows 3D view of pressure transducer, all drawing and view are sketched in solid work.

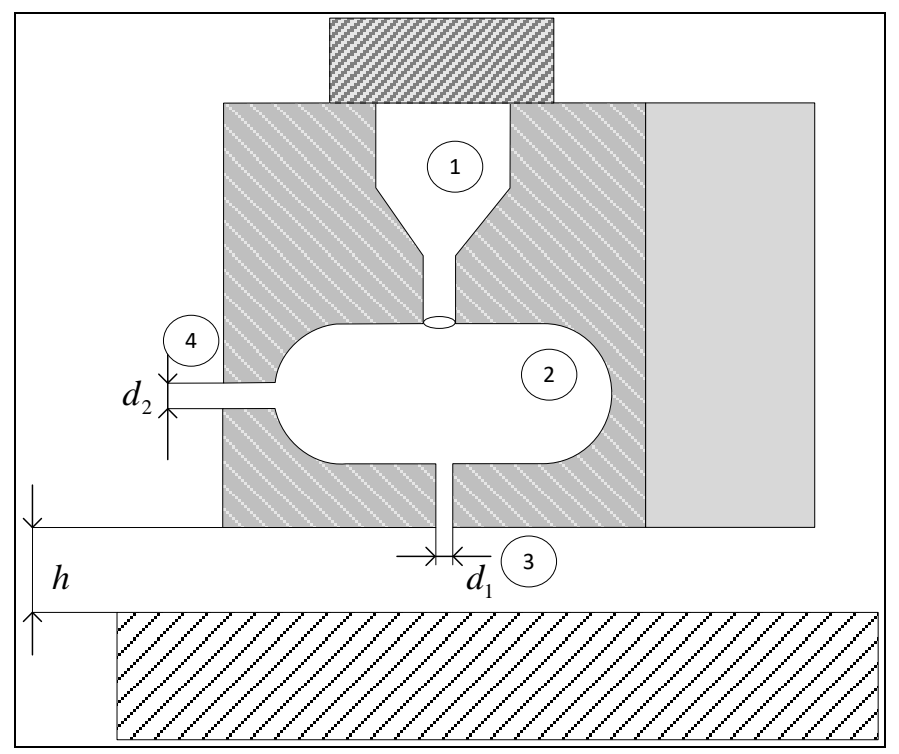

Figure 4 Schematic view of a pressure sensor with (1) pressure transducer, (2) cylindrical chamber, (3) outlet and (4) inlet for supply pressure. 




Figure 5. (a) Top view, (b) 3D view, (c) cross-sectional view of (d) pressure transducer in solid work.

The active aerostatic bearing with two embedded pressure transducer is shown in Figure 6. All components are designed in solid work, including a pressure sensor, mounting for pressure transducer and aerostatic pad. The material is aluminium due to lightweight and good stiffness. Pressure transducer belongs Honeywell with model $40 \mathrm{PC} 150 \mathrm{G} 2 \mathrm{~A}$ which is preferred due to its high accuracy of $0.2 \%$, higher range of pressure measuring $150 \mathrm{psi}$ and due to its ability of fully signal condition that enables it for easy interfacing with Arduino board. It is also preferred for interfacing with Arduino board due to its ability giving a sensitivity of $26.6 \mathrm{mV} / \mathrm{psi}$

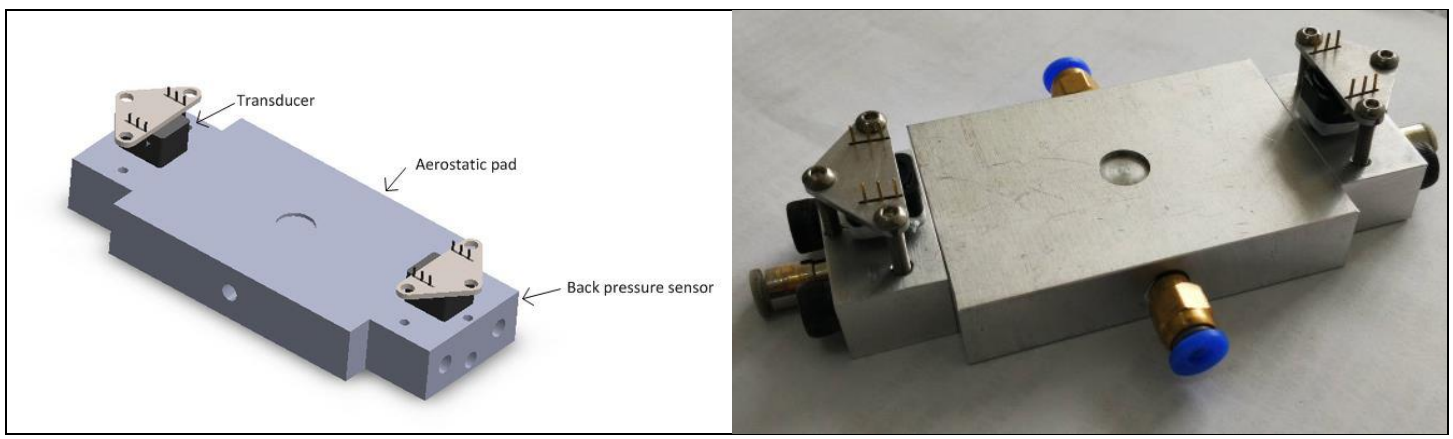

Figure 6. Solid works drawing for aerostatic bearing.

\section{EXPERIMENTAL SETUP}

In order to check the efficiency of aerostatic bearing a self-designed prototype is shown in Figure 7. It consists of different components as labelled: (1) Compressor: a mechanical device that increases the pneumatic pressure by compressing air. It can provide max pressure of from $0.4 \mathrm{Mpa} \rightarrow 0.6 \mathrm{Mpa}$ with a flow rate of 30 liter per minute. (2) Telemetry Viewer: a Java based software which helps to visualise data that is given 
by Arduino UNO. It is helpful for data logging. It shows live data from Arduino. In order to make visualization of data on telemetry viewer, both Arduino and telemetry viewer should be connected to the same com port of the computer, and also baud rate for serial communication should be same. (3) Pneumatic pressure regulator: a type of pressure reducing valve. It maintains constant pressure in a system of compressed air regardless of variations in output flow or input pressure. Currently, the system is equipped with three pressure regulator gauges that maintain constant pressure against the pneumatic cylinder, pressure sensor and aerostatic bearing. In case of a pneumatic cylinder, it is used to provide variable load by varying pressure. (4) Pneumatic flow regulators: a type of flow reducing device that maintains a constant flow which is required by the system. Currently, the system is equipped with three flow regulator devices. (5) Mini Pneumatic solenoid valve: a high-speed electro-pneumatic solenoid valve which has a response time for opening $3 \mathrm{~ms}$ and closing $1.5 \mathrm{~ms}$ by operating at a maximum frequency of $200 \mathrm{~Hz}$.

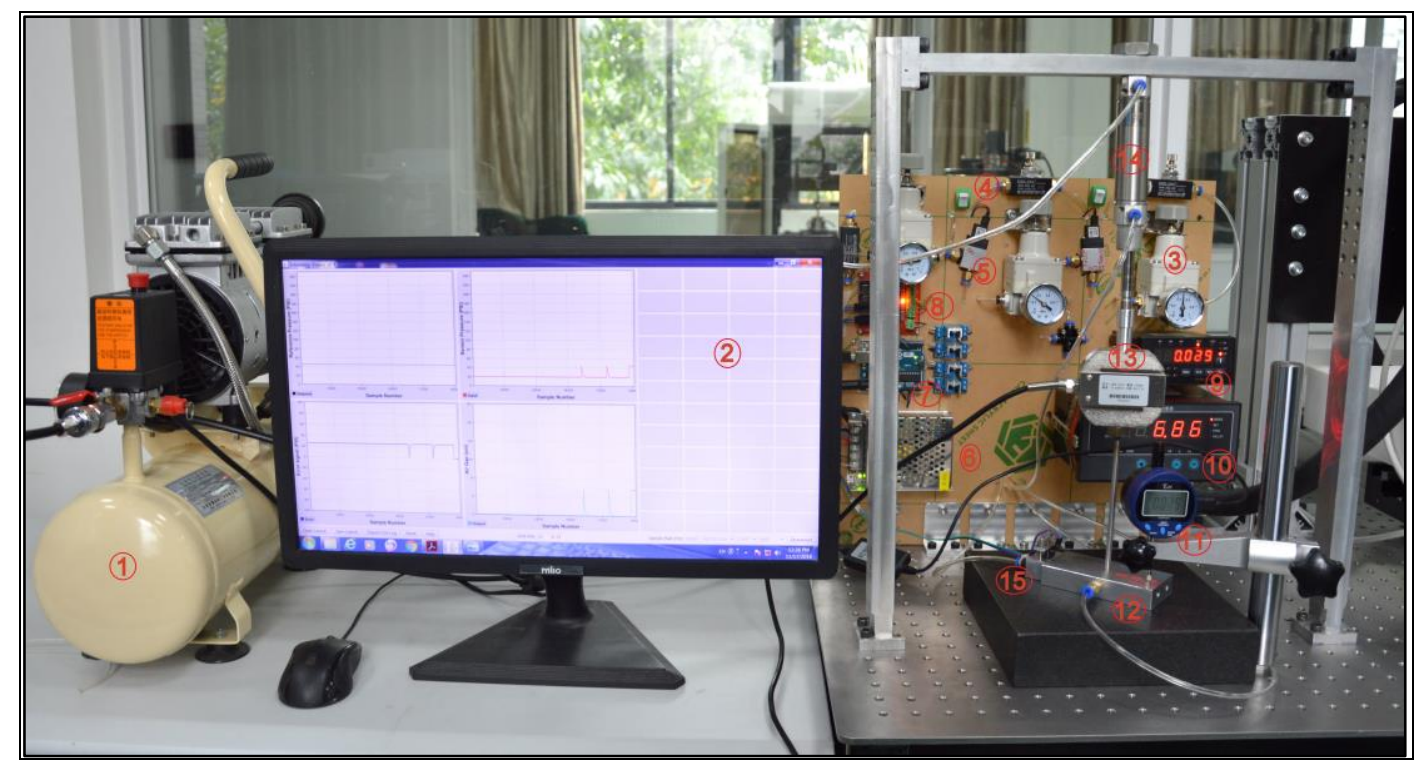

Figure 7 Experimental setup.

The valve operates with pulse width modulation. The different types of pulse width modulation are shown in Figure 8. On the graph, the green line shows a regular time period. The duration of this period can be obtained by taking the inverse of PWM frequencies for assigned pins. PWM pins are controlled by three timers. Pin D3 and D11 controlled by timer 2 and have a default frequency of $490.20 \mathrm{~Hz}$ (default). Similarly, Pin D9 and D10 controlled by timer 1 and have a default frequency of $490.20 \mathrm{~Hz}$ (default). D5 and D6 controlled by timer zero and have a frequency of $976.56 \mathrm{~Hz}$ (default). The program code is using pin D5 and pin D6 as PWM pins. The high-speed electropneumatic valve does not operate a frequency greater than $200 \mathrm{~Hz}$. One line code has been written before have to initialize PWM pin as an output (pinMode(pin, OUTPUT)). This code is given by TCCR0B $=$ TCCR0B \& B11111000 | B00000101. This one-line command changes the frequency from $976.56 \mathrm{~Hz}$ into $61.04 \mathrm{~Hz}$. Arduino PWM pin with a frequency of $61.04 \mathrm{~Hz}$, the green lines would measure 16.3 milliseconds each.

6) Power supply: it has a rating of $24 \mathrm{~V}, 2 \mathrm{~A}$. The mini solenoid valve use $24 \mathrm{~V}$ while other components use $5 \mathrm{~V}, 9 \mathrm{~V}$ and $12 \mathrm{~V}$. So, a number of step-down converters have been used at its output. (7) Arduino uno: it is a microcontroller based open source 
controller. It is programmed in the Arduino IDE compiler. It takes input from the pressure sensor in the form of analog data and control the input and output valves with help of PWM signals. It generates PWM signals of different duty cycles to control the flow through mini solenoid valves. Furthermore, it is connected to telemetry viewer to get online results. (8) 4 channel MOSFET switch: Arduino uno does not have enough power to drive mini solenoid valves which require $24 \mathrm{~V}$ while Arduino uno has only $5 \mathrm{~V}$. So this drive circuit has dual role one it drives high-speed solenoid valves and second it isolate solenoid valve from the arduino uno board. This 4 channel MOSFET switch based on FET IRF540.

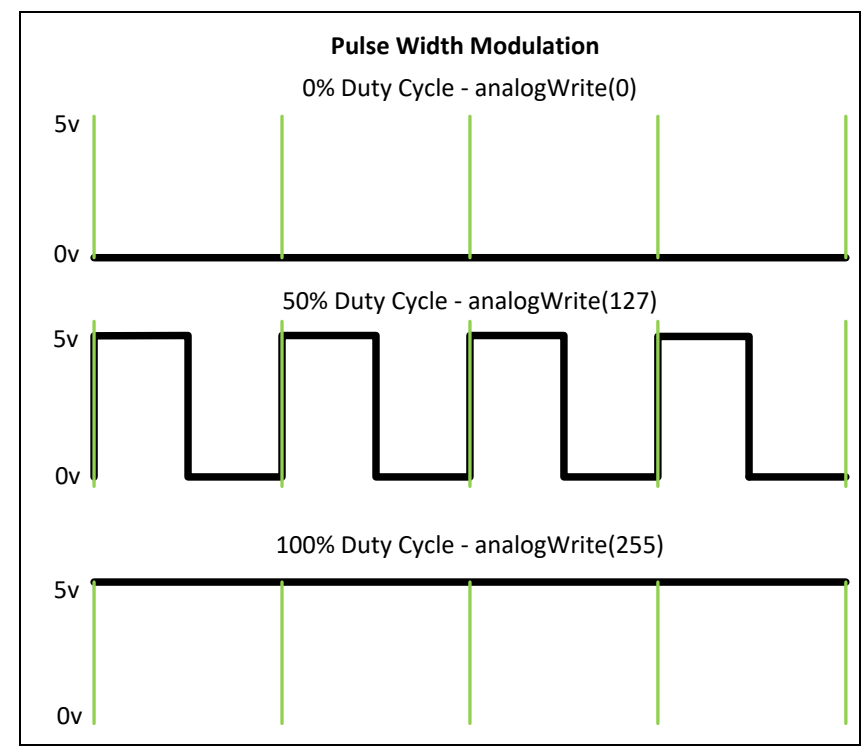

Figure 8. PWM signals with different duty cycles.

(9) Display box for displacement: it takes data from the digital indicator and displays it. It also transmits data through serial communication to a computer and displays it in data monitor software in computer. (10) Display box for force: it takes data from the load cell and displays it in the form of newton, gram, kilogram and tons. It has good calibration characteristics such as; automatic zero calibration, automatic range adjustment, no weight calibration, manual tuning, fine-tuning and trim coefficient. (11) Digital dial indicator: it is a device which can measure air height gap from $0 \rightarrow 12 \mathrm{~mm}$ with a resolution of $1 \mathrm{um}$. It can be connected to multiple devices such as PLC, computer and display boxes with the help of data cable. (12) Aerostatic Pad. 13 Load cell: it is basically transducer which generates an electrical signal whose magnitude has directly proportional to the load or force applied to it. A strain gauge based load cell has been used which can measure up to $100 \mathrm{~kg}$ load. It is connected to display for reading. (14) Pneumatic cylinder: it applies point load on the aerostatic bearing with the help of pneumatic supply and its speed is controlled by the flow regulator while its given force is controlled by the pressure regulator and its force is measured by a load cell. (15) Pressure sensor: it is a self-designed sensor equipped with Honeywell pressure transducer 40PC150G2A. It gives $26.6 \mathrm{mv} / \mathrm{psi}$. Its output is converted into pressure by following codes;
i. float SensorData $=$ analogRead(A0)
ii. float voltage $=($ SensorData/1024 $) * 5.0$
iii. float Pressure $=($ voltage/0.0266 $)$ 


\section{DYNAMIC CHARACTERISTICS OF VALVES}

Dynamic characteristic of the valve is verified by measuring average flow against the pressures. The different pressures are provided with gauge supply pressure that varies from 0 to $0.4 \mathrm{MPa}$. The valve is attached to a pressure regulator for varying pressure. Valve characteristics were checked under different frequencies of $50 \mathrm{~Hz}$ and $100 \mathrm{~Hz}$ which are obtained by using the proper delay in the programming code for Arduino. PWM is a main square wave signal generated by a controller which is used to drive electropneumatic valves. A proper delay is used in the code to generate different PWM with different frequencies. Curves are obtained with PWM under different frequencies and different duty cycles. The graph shown in Figure 9 verified dynamic characteristics of pneumatic solenoid valves.

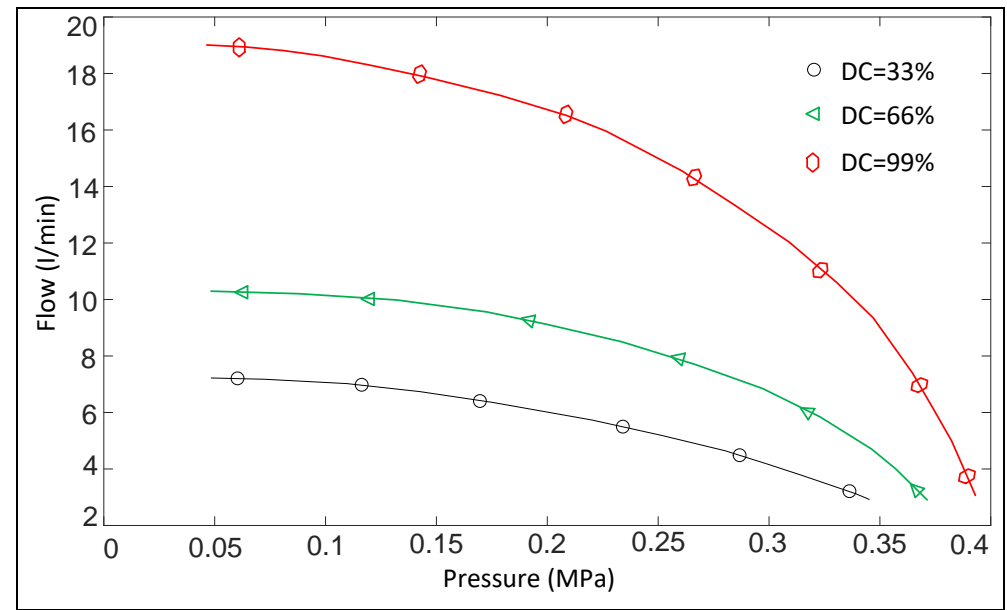

(a) $50 \mathrm{~Hz}$



(b) $100 \mathrm{~Hz}$

Figure 9. Airflow through the valve against different pressures.

\section{RESULTS AND DISCUSSION}

Aerostatic bearing is connected to an Arduino board and program code is written in Arduino IDE software and transferred to the Arduino board through the USB interface. Two types of control system are designed. 


\section{Open Loop Control}

In this type of control system, a program code is written in Arduino IDE and transferred to the Arduino board through a USB interface. In this control loop, an air gap of $45 \mu \mathrm{m}$ is maintained by switching valves with pwm signal. Input valve is kept at 100 duty cycle (valve is always on) while Output valve is kept at $50 \%$ duty cycle. The analogWrite() command is used to produce different duty cycles on a scale of 0-255. The analogWrite(255) demands a $100 \%$ duty cycle (that mean always on) while analogWrite(127) shows 50\% duty cycle (on for half of the time). In order to check disturbance rejection or load rejection performance, a load of $60 \mathrm{~N}$ and $120 \mathrm{~N}$ are applied through the pneumatic cylinder and measured through load cell. Air gap changes when an external load force is applied. The air gap is $45 \mu \mathrm{m}$ when there is no load, but reduces to $30 \mu \mathrm{m}$ when a $60 \mathrm{~N}$ load is applied similarly reduces to $15 \mu \mathrm{m}$ when a $120 \mathrm{~N}$ load is applied. Results with open-loop control system are taken through Telemetry viewer which is connected through serial communication at a 9600 baud rate to receive data and are shown in Figure 10. The result shows that the change in the air gap is $15 \mu \mathrm{m}$ for each increment of $60 \mathrm{~N}$ load force. Also, the system does not get back its original equilibrium position after being applied load. This drawback was overcome in the next part using a feedback control system.

\section{Closed-Loop Control}

In this type of control system, a program code is written in Arduino IDE and transferred to Arduino UNO through the USB interface. In the program, first of all, variables are declared then it reaches to the setup function which is called to program code only once. In the setup function, a serial port is opened at a baud rate of 9600 bits/second for displaying the values. After that pin 5 and pin 6 is assigned for output while pin A0 is assigned for input. Next part of the program code is a loop function. The loop function runs repeatedly. In the loop function, first of all, data is read from analogue pin A0. Data from the sensor is not in the form of pressure. A formula has been used to covert input sensor data into pressure. It is given by;

$$
\left\{\begin{array}{l}
\text { Voltage }=\text { Sensordata } \times\left(5 / 2^{10}\right) \\
\text { pressure }=\frac{\text { Voltage }}{0.0266}
\end{array}\right.
$$

ADC in Arduino UNO is 10 bits and input to the sensor is 5 volts. So, that is why 5 volts are divided by $2^{10}$. Then multiply by sensor data to get the output valve from the sensor in the form of voltage. According to the datasheet of 40PC150G2A, Pressure sensor gives $26.6 \mathrm{mV}$ per psi. The voltage is divided by 0.0266 volts to get pressure in psi. In order to convert pressure into the air height gap, a formula has been derived. This formula relates pressure with an air height gap that exists under the aerostatic bearing. Here is a simple derivation for it. It is found that pressure is $33 \mathrm{psi}$ and $31.22 \mathrm{psi}$ when the air gap height is at zero and $45 \mu \mathrm{m}$. So there are two points which can be described by two sets $(33,0)$ and $(31.22,45)$. The rate at which pressure is decreasing and air gap height is increasing is given by Eq. (2). 


$$
\text { Rate }=\frac{(31.22-33)}{(45-0)}=-0.0395
$$

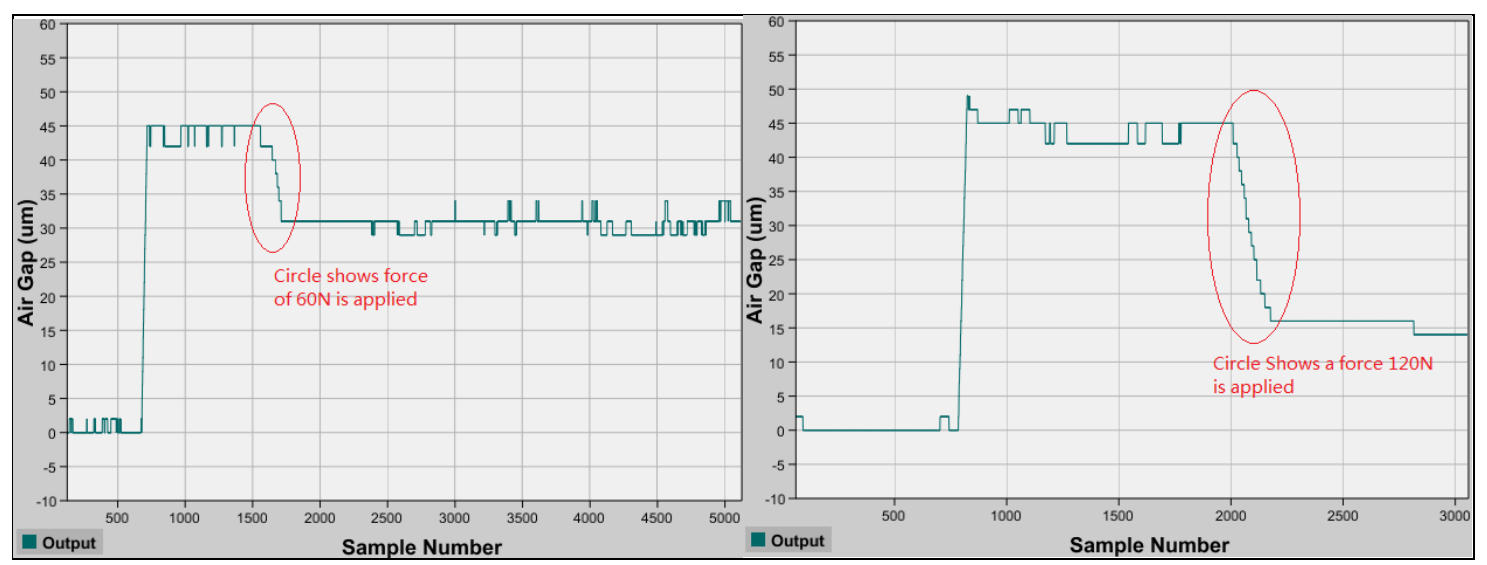

(a)

(b)

Figure 10. Open-loop response against (a) $60 \mathrm{~N}$ and (b) $120 \mathrm{~N}$ load.

One can easily obtain the equation of a line by using rate and set of points;

$$
\text { pressure }=-(0.0395) \times \text { Air gap height }+33
$$

The output is an air height gap and the input variable is pressure, which varies by the pressure sensor. So, rearranging Eq. (3);

$$
\text { Air gap height }=\frac{33-\text { pressure }}{(0.0395)}
$$

Equation (4) develops the relation between air height gap and pressure data which is given by the sensor. The sensor's output has a noise that is removed by taking the average of output signals for 10 latest readings from the sensor. The flow chart for the program which is used to smooth output signal is shown in Figure 11(a). There are three loops in the program. The first loop is present in the setup function of the Arduino IDE. The first loop runs only once and it creates an array of 10 integers and all integers have initial values of zero. The second loop reset value of an integer $j$ to zero when it is equal to ten or greater than ten. The reason behind this is that we want to run loop only 10 times, which means that taking an average of latest ten readings from the sensor. The second loop is sub-loop which is present in the third loop. The third loop basically represents the void loop of Arduino UNO and it runs repeatedly. In the third loop, the previous reading of sensor is subtracted from total value then next new reading is read from the sensor. This new reading is added to the total in the next step after that second loop comes. The average is calculated after being operated by the second loop. This average reading shows the sensor data with less noise. This smooth data is used by Eq. (1)-(4) to relate sensor data with voltage, pressure and air height gap. In order to implement closed-loop control, a program code is written. The logic of this program code in the form of a flow chart is shown in Figure 11(b). The received data is sent to the telemetry viewer to visualize in a computer. Telemetry viewer is set up for the same baud rate which is written in program 
code. The computer serial port for Arduino UNO and telemetry viewer should be same. The data samples are received at a given baud rate in telemetry viewer and plotted against different variables. In order to check the effectiveness of proposed active aerostatic bearing, a load of $60 \mathrm{~N}, 120 \mathrm{~N}$ and $180 \mathrm{~N}$ is provided through the pneumatic cylinder and measured with a load cell. It is found that changes in air film is $15 \mu \mathrm{m}, 30 \mu \mathrm{m}$ and $45 \mu \mathrm{m}$ with applying $60 \mathrm{~N}, 120 \mathrm{~N}$ and $180 \mathrm{~N}$ force that shows a linear and robust behaviour of aerostatic bearing with respect to the external force.

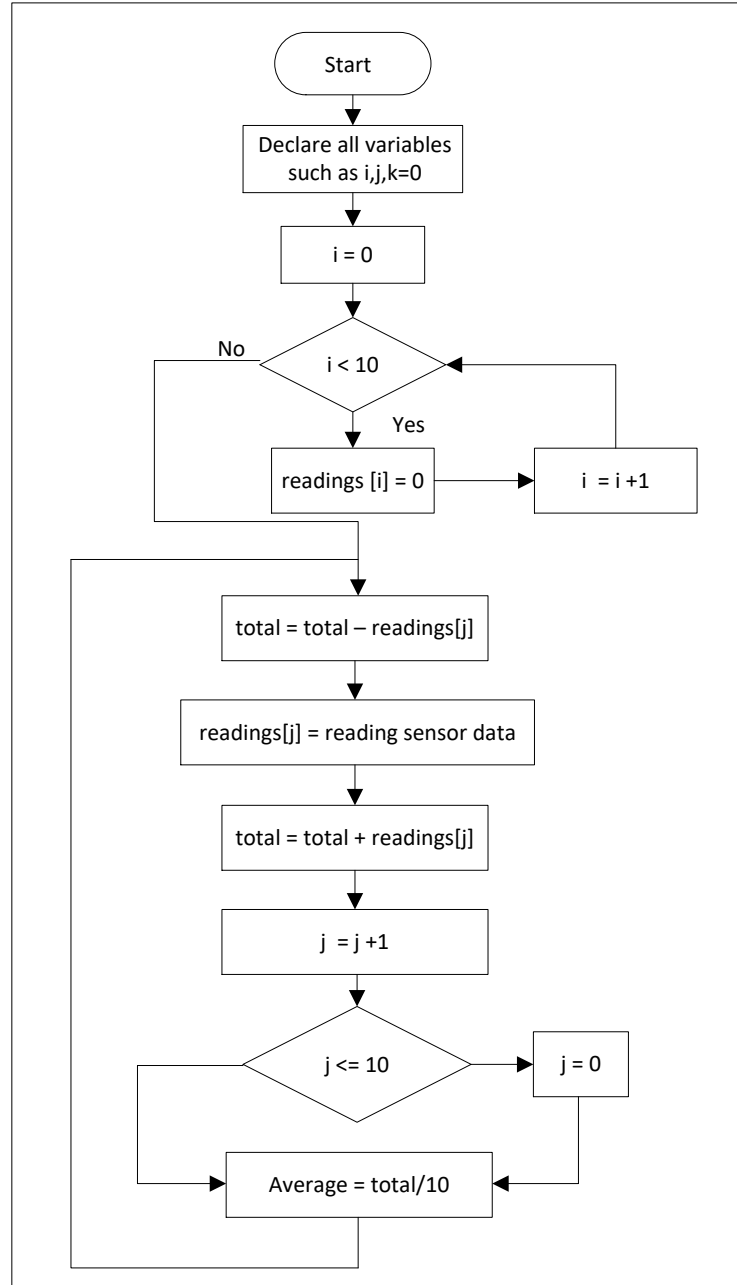

(a) smoothing data

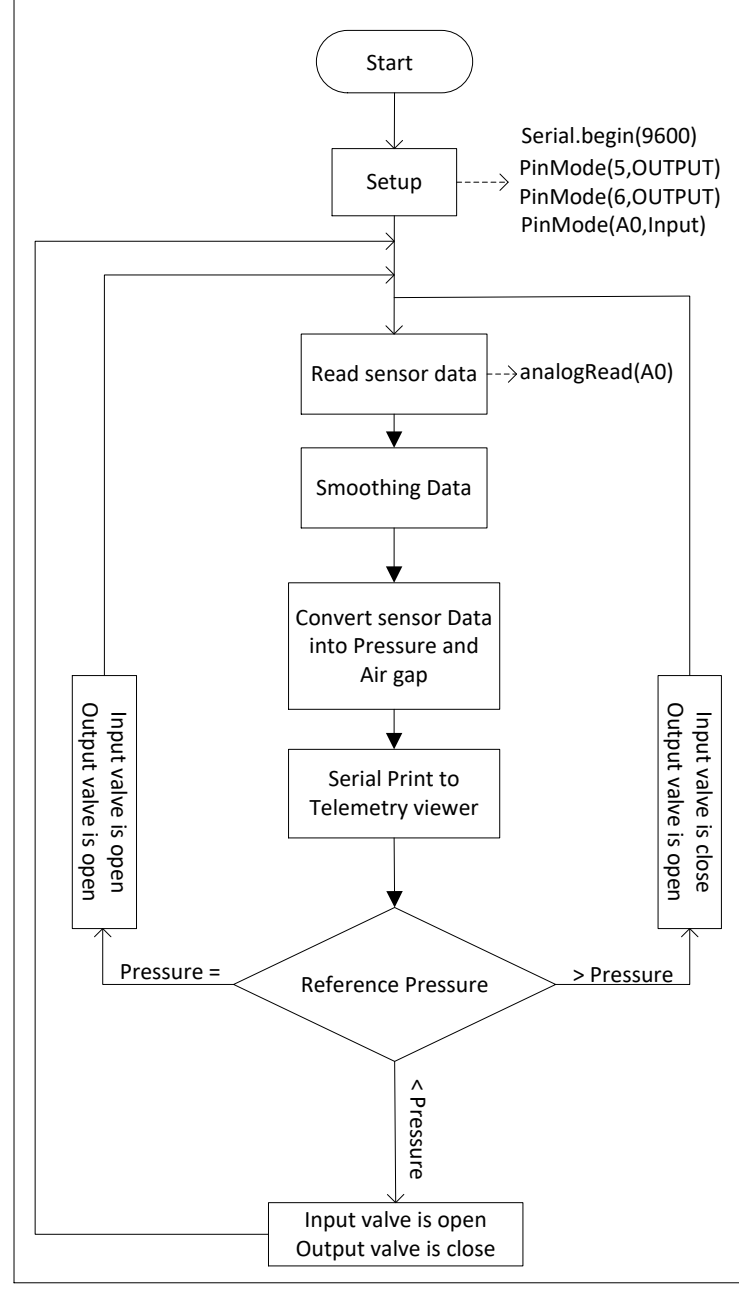

(b) closed loop control

Figure 11. Program code logic in the form of flow chart.

The behaviour of aerostatic bearing against external force is shown in Figure 12, Figure 13 and Figure 14. It clearly shows that when an impact force acts on the aerostatic bearing, it produces changes in the film thickness of the air gap. It is found that there is a change in air gap which is $15 \mu \mathrm{m}$ for each and every increment of $60 \mathrm{~N}$ load force and also system gains back original equilibrium position that is clearly a big advantage of closed-loop control system over the open-loop system. So that is why aerostatic bearing with closed-loop configuration are preferred in an application where control of eccentricity is very important. 

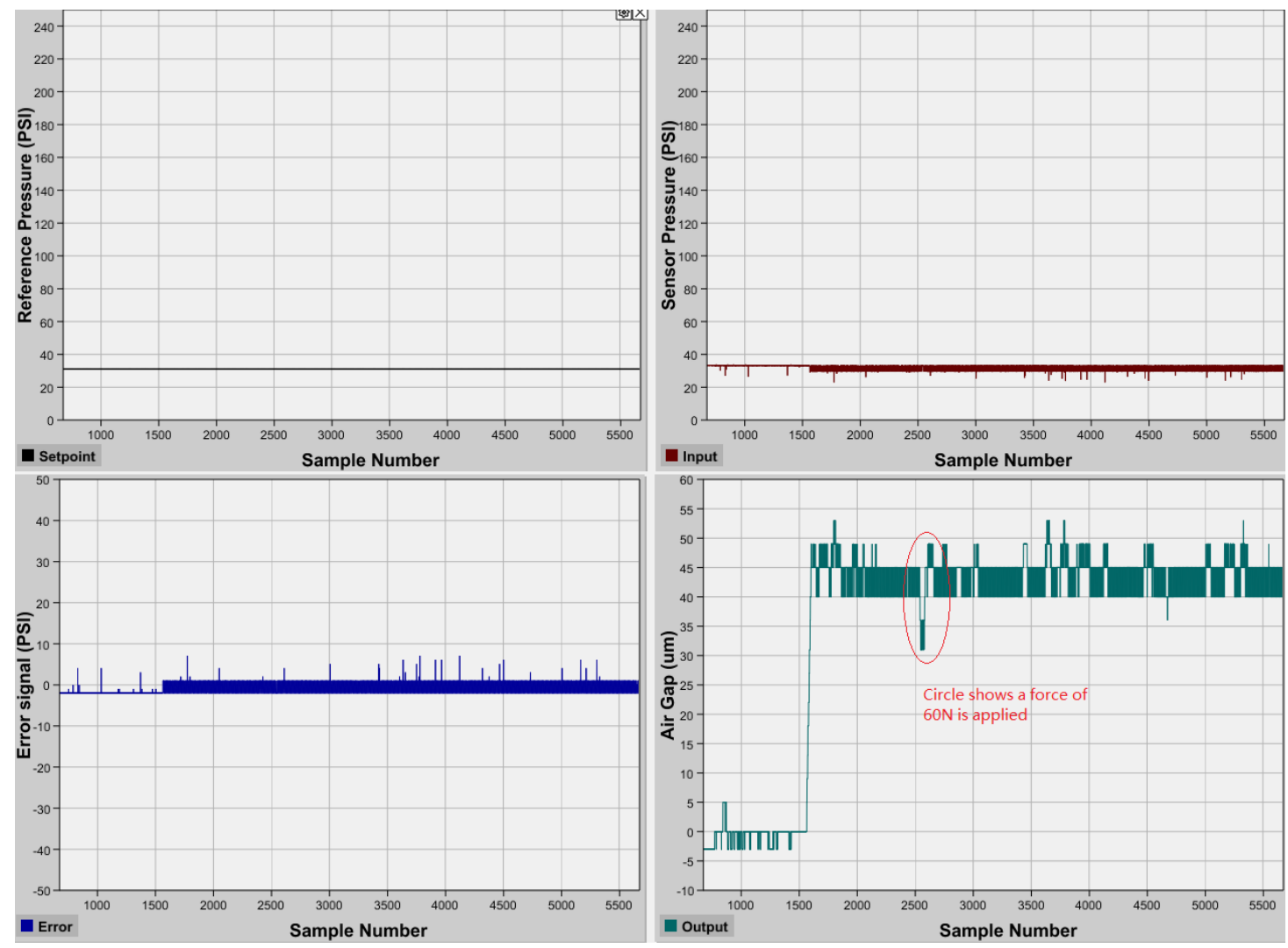

Figure 12. Responses of aerostatic bearing under $60 \mathrm{~N}$ force.
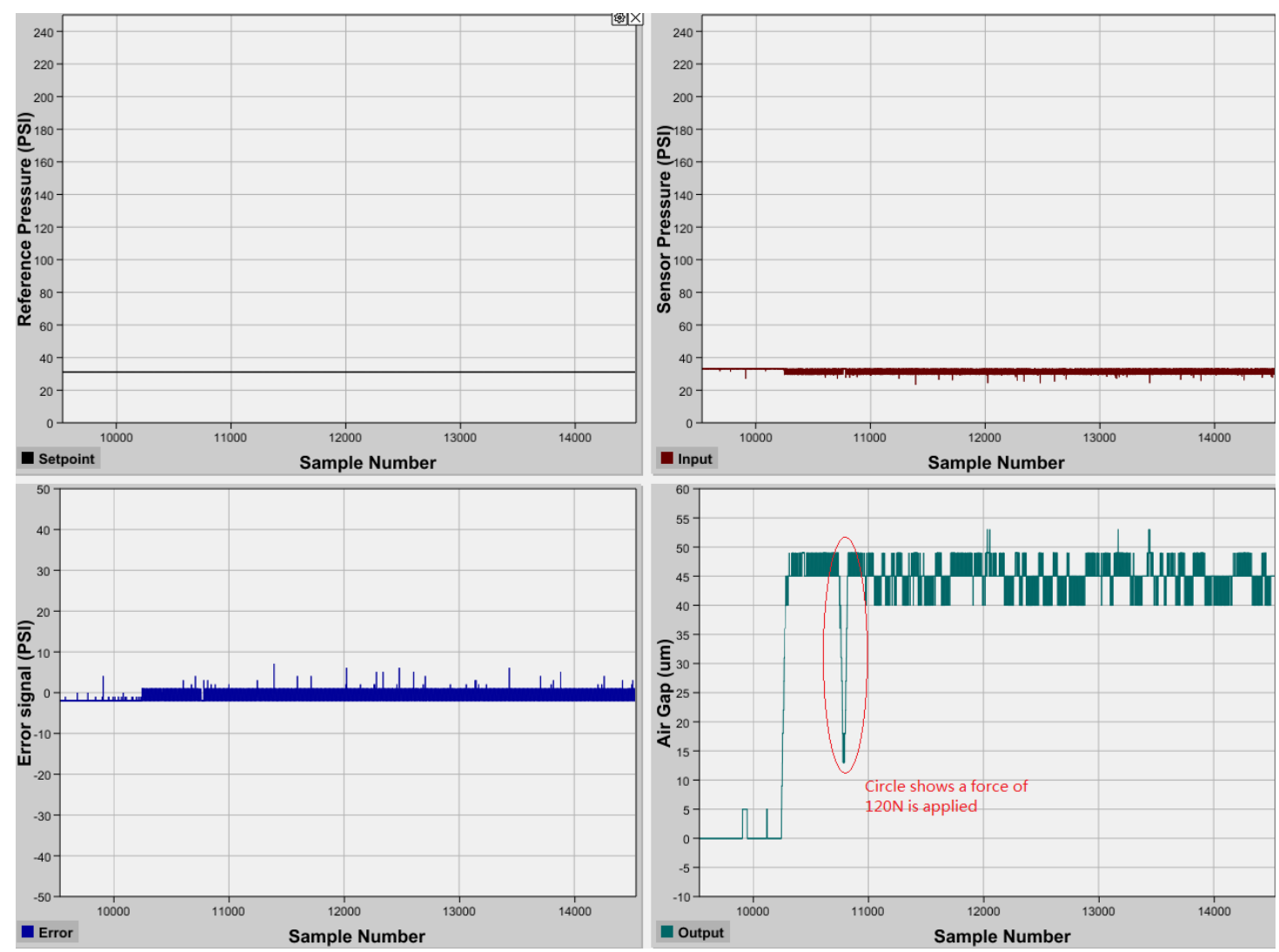

Figure 13. Response of aerostatic bearing under $120 \mathrm{~N}$ force. 

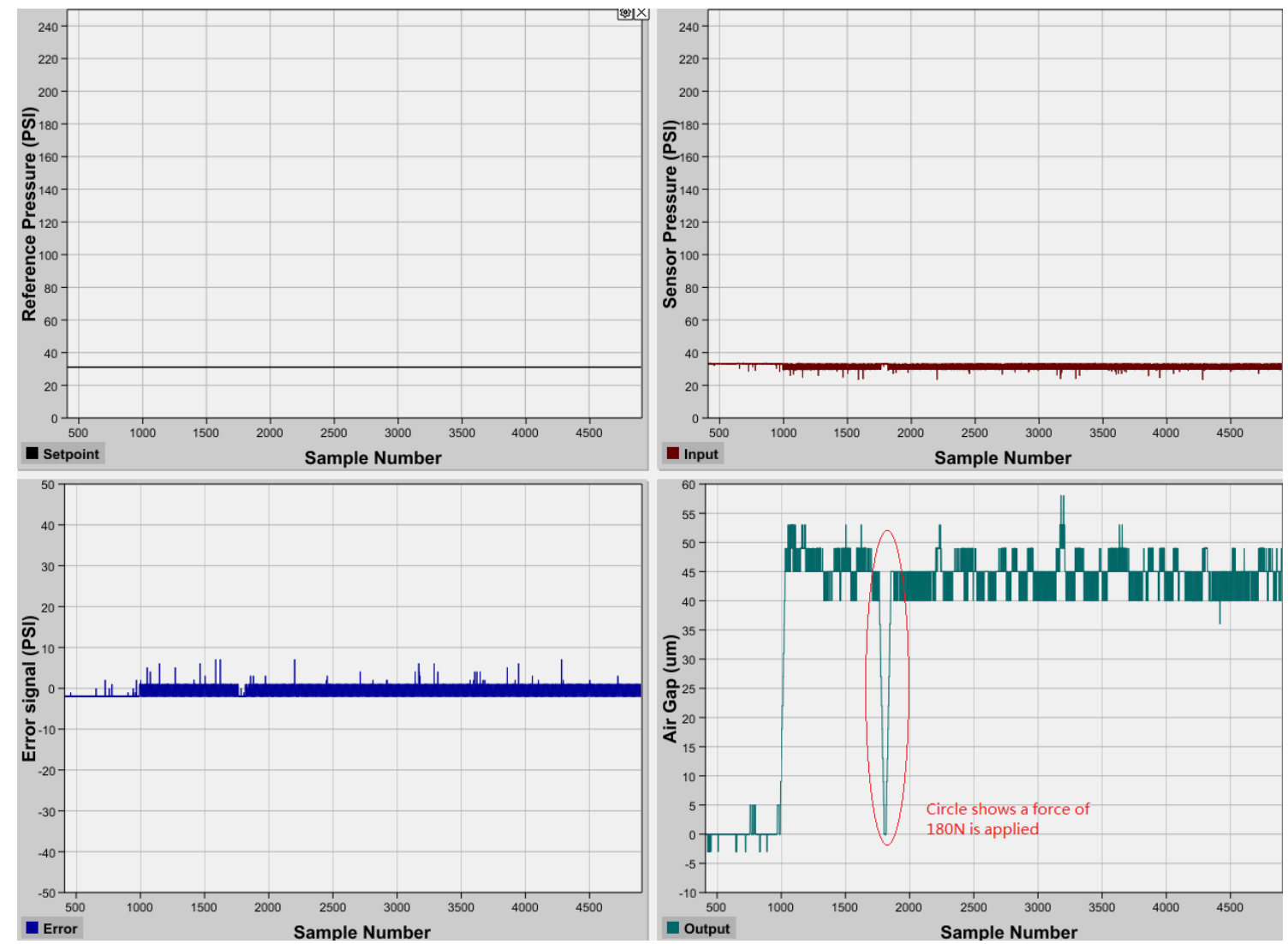

Figure 14. Response of aerostatic bearing under $180 \mathrm{~N}$ force.

\section{CONCLUSION}

An active aerostatic thrust bearing is proposed and developed in current research work that consists of an aerostatic pad and embedded back pressure sensor which are designed in solid work and manufactured with high precision machining process with the help of 3D drawings in solid work. Embedded backpressure sensors are used to feedback the height of an air gap that formed under the aerostatic pad. The prototype is tested under open-loop as well as closed-loop configuration. Results show that the proposed system has effectiveness in friction control for different types of translation and linear motion applications such as guiding ways. The proposed system has good rejection performance against impact load, can obtain quickly equilibrium position after applied load. A comparison of open-loop and closed-loop result shows that proposed aerostatic bearing ensure zero eccentricity under closed-loop configuration and enable the system to achieve the original equilibrium position. The prototype has good performance, further tests can be carried for a full understanding of dynamic and static behaviour of the prototype, and further optimal performance can be achieved by probably new optimal design.

Although the efficiency of this aerostatic bearing in term of bandwidth is low as compared to other PZT aerostatic bearings the advantage of being cheap cannot be ignored and can be used widely at commercial scale due to less expensive. 


\section{ACKNOWLEDGEMENT}

This work is carried out with the help of School of Mechanical Engineering, Chongqing University China as well as supported by the National Natural Science Foundation of China under grant No.51075409, grant No.51775062 and grant No. 51405044.

\section{REFERENCES}

[1] Snoeys R, Al-Bender F. Development of improved externally pressurized gas bearings. KSME Journal. 1987;1:81-8.

[2] Bryant MR, Velinsky SA, Beachley NH, Fronczak FJ. A design methodology for obtaining infinite stiffness in an aerostatic thrust bearing. Journal of Mechanisms, Transmissions, and Automation in Design. 1986;108:448-53.

[3] Holster P, Jacobs J. Theoretical analysis and experimental verification on the static properties of externally pressurized air-bearing pads with load compensation. Tribology international. 1987;20:276-89.

[4] Sato K, Yamada K, Togo S, Saito Y, Unno K. Study on externally pressurized gas bearings with infinite stiffness (2nd report) experiments on the static characteristics of a circular thrust bearing. Journal-Japan Society For Precision Engineering. 1996;62:85-9.

[5] Chen M-F, Lin Y-T. Dynamic analysis of the X-shaped groove aerostatic bearings with disk-spring compensator. JSME International Journal Series C Mechanical Systems, Machine Elements and Manufacturing. 2002;45:492-501.

[6] Moradi M, Colombo F, Raparelli T, Trivella A, Viktorov V. Dynamic lumped model of externally pressurized rectangular air bearings. Precision Engineering. 2018.

[7] Colombo F, Lentini L, Raparelli T, Trivella A, Viktorov V. Dynamic model of a grooved thrust bearing: numerical model and experimental validation. Proceeding of the 23rd Conference of the Italian Association of Theoretical and Applied Mechanics, AIMETA2017. p. 506-17.

[8] Rehman WU, Luo Y, Wang Y, Jiang G, Iqbal N, Rehman SU, et al. Fuzzy logicbased intelligent control for hydrostatic journal bearing. Measurement and Control. 2019;52:229-43.

[9] Rehman WU, Jiang G, Luo Y, Wang Y, Khan W, Rehman SU, et al. Control of active lubrication for hydrostatic journal bearing by monitoring bearing clearance. Advances in Mechanical Engineering. 2018;10:1687814018768142.

[10] Belforte G, Raparelli T. Development of a new actively compensated pneumatic journal bearing. 1995.

[11] Sato Y, Maruta K, Harada M. Dynamic characteristics of hydrostatic thrust air bearing with actively controlled restrictor. Journal of tribology. 1988;110:156-61.

[12] Mizumoto H, Arii S, Kami Y, Goto K, Yamamoto T, Kawamoto M. Active inherent restrictor for air-bearing spindles. Precision Engineering. 1996;19:141-7.

[13] Mizumoto H, Matsubara T, Yamamoto H, Okuno K, Yabuya M. An infinitestiffness aerostatic bearing with an exhaust-control restrictor. Progress in Precision Engineering: Springer; 1991. p. 315-6.

[14] Mizumoto H, Shimizu T. An infinite-stiffness aerostatic spindle with active restrictors. Journal-Japan Society For Precision Engineering. 1993;59:607-. 
[15] Aguirre G. Dynamic stiffness compensation with active aerostatic thrust bearings. Proceedings of ISMA 2008, International Conference on Noise and Vibration Engineering, Leuven, 15-17 Sept2008.

[16] Aguirre G, Al-Bender F, Van Brussel H. A multiphysics coupled model for active aerostatic thrust bearings. Advanced Intelligent Mechatronics, 2008 AIM 2008 IEEE/ASME International Conference on: IEEE; 2008. p. 710-5.

[17] Aguirre G, Al-Bender F, Van Brussel H. A multiphysics model for optimizing the design of active aerostatic thrust bearings. Precision Engineering. 2010;34:507-15.

[18] Al-Bender F. On the modelling of the dynamic characteristics of aerostatic bearing films: From stability analysis to active compensation. Precision Engineering. 2009;33:117-26.

[19] Morosi S, Santos IF. Active lubrication applied to radial gas journal bearings. Part 1: Modeling. Tribology International. 2011;44:1949-58.

[20] Aoyama H, Watanabe I, Akutsu K, Shimokohbe A. An ultra precision straight motion system (1st report). Journal-Japan Society For Precision Engineering 1988;54:558-63.

[21] Matsumoto H, Yamaguchi J, Aoyama H, Shimokohbe A. An ultra precision straight motion system (2nd report). Journal- Japan Society of Precision Engineering 1988;54:1945-50.

[22] Horikawa O, Shimokohbe A. An active air bearing: control of radial axis motion and stiffness. JSME International Journal Ser 3, Vibration, Control Engineering, Engineering For Industry. 1990;33:55-60.

[23] Belforte G, Colombo F, Raparelli T, Trivella A, Viktorov V. Comparison between grooved and plane aerostatic thrust bearings: static performance. Meccanica. 2011;46:547-55.

[24] Belforte G, Raparelli T, Viktorov V, Trivella A. Discharge coefficients of orificetype restrictor for aerostatic bearings. Tribology International. 2007;40:512-21.

[25] Colombo F, Raparelli T, Viktorov V. Externally pressurized gas bearings: a comparison between two supply holes configurations. Tribology International. 2009;42:303-10.

[26] Belforte G, Colombo F, Raparelli T, Trivella A, Viktorov V. High-speed electrospindle running on air bearings: design and experimental verification. Meccanica. 2008;43:591-600.

[27] Raparelli T, Viktorov V, Colombo F, Lentini L. Aerostatic thrust bearings active compensation: Critical review. Precision Engineering. 2016;44:1-12.

[28] Belforte G, Raparelli T, Viktorov V, Trivella A. Analysis of steady and transient characteristics of pneumatic controlled air bearing. Proceedings of the JFPS International Symposium on Fluid Power: The Japan Fluid Power System Society; 2002. p. 699-704.

[29] Huang K, Shiao Y. Design and development of magnetostrictive actuating restrictor for aerostatic thrust bearing. In: $12^{\text {th }}$ IFToMM World Congress: Citeseer; 2007. p. 18-21.

[30] Ro S-K, Kim S, Kwak Y, Park CH. A linear air bearing stage with active magnetic preloads for ultraprecise straight motion. Precision Engineering. 2010;34:186-94.

[31] Elias N, Yahya N. Simulation study for controlling direct current motor position utilising fuzzy logic controller. International Journal of Automotive and Mechanical Engineering. 2018;15:5989-6000. 
[32] Aalizadeh B, Asnafi A. Fuzzy versus neuro-fuzzy identification of active front steering of a vehicle on slippery roads. International Journal of Automotive and Mechanical Engineering. 2019;16:6078-89.

[33] Rahman TA, As'arry A, Jalil NA, Kamil R. Dynamic modelling of a flexible beam structure using feedforward neural networks for active vibration control. International Journal of Automotive and Mechanical Engineering. 2019;16:626380.

[34] Abidin AZ, Sawing T, Mohamaddan S, Halim H, Annisa J, Muslimen R, et al. Energy Harvesting from Rotating Motion of In-Pipe Robot Cleaning Device. International Journal of Automotive and Mechanical Engineering. 2019;16:642736. 